\title{
Relationship between emotional labor, work stress, employee creativity, and turnover intention: study on Indonesian bank frontliners
}

\author{
Devi Intan Satyaningrum ${ }^{1}$ and Indi Djastuti ${ }^{1}$ \\ ${ }^{1}$ Department of Management, Faculty of Economics and Business, Universitas Diponegoro, Indonesia
}

\begin{abstract}
This study examines the effects of emotional labor on work stress, employee creativity and turnover intention, and examines the role of work stress as a mediator. The study was conducted in a limited way to the 90 employees of the Semarang branch of the BTN bank frontliners. The analysis using SEM PLS suggested that emotional labor had a positive effect on work stress and turnover intention but was not significant on employee creativity. Furthermore, work stress has a negative effect on employee creativity and a positive effect on turnover intention, and in this study proves that work stress mediated the influence of emotional labor on employee creativity and on turnover intention.
\end{abstract}

Keywords emotional labor; work stress; employee creativity; turnover intention

\section{INTRODUCTION}

Revolution of services has been adopted by most service companies including banks that have promoted emotional labor become one of the most prominent issue. According to Andrew, Morris and Feldman (1996), emotional labor was the effort, planning and control needed to display the emotions that were desired organizationally during interactions with customers. Grandey (2000) argues that emotional labor was the process of regulating feelings and expressions for organizational goals. Desired emotions are basically synchronized with the form expected by the organization, but most of them were not aligned with those felt by employees. While Brennan \& Brannan (2005) saw the concept of emotional labor from a monetary perspective by defining it as management of feelings carried out as part of paid work, which serves the interests of entrepreneurs in maximizing surplus value.

There was no denying that there were attempts made by front-line officers to hide what was felt to meet organizational expectations including expressing, restraining, strengthening themselves or pretending to adjust the true emotions to align with the job requirements. This was a kind of forced labor that can cause emotional dissonance because the feelings that were truly felt were contrary to the norms of the appearance of the organization. The condition resembled conflict management role of the individual or an impression because it involved a deliberate effort on the part of individuals to direct their behavior towards other people to cultivate the social perception of itself and certain interpersonal climate (Zapf, 2002). Furthermore, Zapf (2002) stated that emotional labor became a phenomenon that could cause emotional exploitation and could cause depression, alienation, fatigue and loss of identity. In order to meet the display rules, employees would be involved in regulating their emotions by using a variety of strategies, namely: surface acting, i.e. actions carried out by someone smiling on their faces without changing their emotions inside, and deep acting, i.e. actions where someone tried to change emotions that were felt deeply.

Emotional labor was associated with employee creativity and turnover intention. Geng, et al (2014) find that surface acting had a negative effect on employee creativity while deep acting had a positive effect on employee creativity. In relation to the turnover intention, surface acting was an effort to forge an emotional display as desired without changing one's internal feelings (Hochschild, Irwin, \& Ptashne, 1983). Employees involved in surface acting felt tension when they felt that they had to display emotions that were different from their authentic emotions. As a result, 
emotional dissonance would occur when employees were involved in surface acting (Biron \& van Veldhoven, 2012). Research on emotional dissonance showed that the experience make inconvenience, and employees were ultimately motivated to stop the situation where emotional dissonance occurred (Abraham, 1999). This dilemma often leads to stressful work roles. In frontline service workplaces, service employees had to maintain appearances to be friendly figures (having fun, friendliness, respect or empathy) to customers, even though the inner feelings they experience might be deemed inappropriate for the role (boredom, dislike or hatred) (Nath, 2011).

The literature showed that work stress was not only a determinant of employee creativity (Schaufeli et al., 2012 ) but also an important mediator between the relationship of contextual factors with employee creativity (Coelho \& Augusto, 2010) and turnover intention even though previous research still showed research gaps, for example, Geng, et.al (2014) reported that surface acting was negatively related to employee creativity while recent research by Shi and Su (2016) and Celikyay and Akgün (2019) found the insignificant relationship. Likewise, for the relationship between surface acting and turnover intention, Shu et al (2018) found that surface acting had a positive effect on turnover intention while Isik and Hamurcu (2017) did not show a significant relationship.

The phenomenon allows the emergence of job stress for frontliner and ended to turnover intention and decreased creativity. With the demands of frontline work that was theoretically emotional labor, and similar research had never been done in Indonesia, it was interesting for research to examine the effects of emotional labor on employee creativity and turnover intention with work stress as intervening variable. In particular emotional labor in this study will only use surface acting dimension.

\section{LITERATURE REVIEW AND HYPOTHESES DEVELOPMENT}

\section{Emotional labor}

Hochschild et al., (1983) called the regulation of one's emotions to comply with work or organizational norms referred to as emotional labor. Ashforth \& Humphrey (1993) define emotional labor as "the act of displaying appropriate emotions". In order to comply with the emotional needs of the organization, service providers needed to practice their role, faked a smile or laugh, and tried to maintain a happy appearance (Karabanow, 1999).

Emotional labor could be considered as a certain type of emotional regulation, where individuals managed or modified their emotions as part of their work role (Grandey, 2000). The boundary between emotional labor and emotional regulation was not clearly defined. However, it was generally accepted that emotional labor was carried out for wages and in the context of work (Grandey, Diefendorff, \& Rupp, 2013).

Emotional labor could be approached from various levels or perspectives in the literature. In understanding the nature of emotional work, it was important to clarify the different perspectives. Grandey et al, (2013) discussed three perspectives where the concept of emotional labor could be investigated, namely: emotional labor as a job requirement, emotional labor as an emotional display, and emotional labor as an intra-psychic experience. While no single perspective was considered correct because each perspective tended to be suitable for a particular discipline.

According to Ashforth and Humphrey (1993) emotional labor as a double-edged sword. On the one hand, emotional labor could facilitate task performance by regulating interactions and blocking interpersonal problems. On the other hand, emotional labor could interfere with performance by prioritizing good service expectations that cannot be met (Ashforth \& Humphrey, 1993). In other words, emotional labor had both positive and negative consequences, especially the impact on the psychological well-being of employees. The negative consequences of emotional labor most frequently cited were fatigue (Andrew Morris \& Feldman, 1996) and job dissatisfaction (Grandey, 2000), decreased self-esteem, depression, cynicism, role alienation, and self-alienation (Wharton, 1999), alienation between self and the role of work, or alienation between self and the role of work that comes to occupation (Hochschild, 1983). While the positive consequences of emotional labor are related to financial reward (salary) 
issues, increased satisfaction, security, and self-esteem (Erickson \& Wharton, 1997); increased self-efficacy and psychological well-being (Ashforth \& Humphrey, 1993); and stress reduction (Conrad \& Witte, 1994), interactions with customers serve as assistance ( Shuler and Sypher, 2000)

\section{Employee creativity}

Creativity was defined as something original and useful-adaptive (Feist, 1998). Some researchers took several different approaches and how to measure creativity better. For example, Amabile (1985) focused on the creativity of a person by examining differences in the intellectual motivation of creative individuals. Runco (2007) saw creativity as a product, something that could be seen and judged by others. These four approaches are called "four $\mathrm{P}$ ".

Employees' creative performance could contribute to organizational effectiveness in a number of ways. The creative performance of employees could improve operations, procedures, products, and services. Studies had found the value in creative performance in employees because creativity had been linked to company performance (Eisenhardt \& Tabrizi, 1995) and profitability (Geroski, Machin, \& VanReenen, 1993)

Additionally, Amabile, Schatzel, Moneta, \& Kramer (2004) found that opportunities for creative work could cause employees to feel more satisfied, and employees who are intrinsically motivated lead to overall employee welfare.

\section{Turnover intention}

Turnover intention referred to attitude orientation or cognitive manifestations of behavioral decisions to quit (Elangovan, 2001). The turnover intention was accepted as one of the most important predictors of behavior, namely the actual decision, which was leaving the company (Yalabik et al., 2017). There were three studies on employee turnover based on the Job Demand-Resources (JD-R) model that was conducted (De Cuyper, et al, 2011), job resources were found to be positively related to engagement (commitment), which in turn reduced intention to leave the company. In addition, the evidence showed a negative relationship between work resources and tension, which in turn increased the intention to leave the company.

De Cuyper et al. (2011) found that the work resources as the most important predictors of employee turnover intentions and suggested that a social support system was needed to maintain a positive attitude, which would help retain the employees. In addition, Jourdain \& Chênevert (2010) found that pressure was negatively related to commitment, which in turn could affect the intention to quit.

Leaving the organization also created an unfavorable situation for the company, because it required the company to find a replacement to fill vacant positions (Blau \& Kahn, 2007). In the context of professional service companies, this might be more of a problem, because professional companies were usually characterized by the ownership of a workforce with a high level of expertise (Olsen et al., 2016). This implies that employees were still a competitive advantage for the company. In other words, employees could play an important role in ensuring business success. In addition, nonhuman assets tended to be relatively insignificant in professional companies (von Nordenflycht, 2010). Thus, it would be very problematic when the company has a high risk of turnover intention. Therefore, it was very important to find ways to keep people alive and win the competition (Boshoff \& Mels, 2000).

\section{Job stress}

Stress is the body's response that was not specific to a claim (Fink, 2009). Anbazhagan, Rajan \& Ravichandran (2013), mentioned a more detailed definition by Tobias Schafer: "Stress was an adaptive response, moderated by individual differences which are the consequences of every action, situation or event that places special demands on someone, who perceives an imbalance between the level of demand given to them and their ability to meet these demands". Cox (1993) defined stress as a perception phenomenon, meaning that stress arose from individual perceptions as they could not handle the demands made.

One form of stress that was widely researched was work stress. Ross (1997) stated that work stress was a form of physiological and emotional arousal experienced by employees when faced with 
situations that threaten or conflict with members of staff or clients. According to Leka et al. (2004), work-related stress was a response that people may have when faced with the work demands and pressures that did not match their knowledge and abilities and challenged their ability to cope.

Cooper, Dewe, and O'Driscoll (2001) argued that sources of work stress could be divided into three groups: specific sources of work, organization, and individual. The first two sources were considered external or environmental factors and the third was an internal factor. Investigation of environmental resources was very interesting for many researchers.

Role conflict and role ambiguity were antecedents of work stress that have been used by many researchers to analyze and measure the stress (Ali, Raheem, Nawaz, \& Imamuddin, 2014; Ram, Khoso Dr., Shah, Chandio, \& Shaikih, 2011; Sheraz, Wajid , Sajid, Qureshi, \& Rizwan, 2014). Role conflict occurred when workers were required to have two or more conflicting behaviors. Role conflict had been proven to have consequences on unpleasant effects on employees and organizations, such as poor job performance, job dissatisfaction, increased turnover intention (Bhatti et al., 2010), and stress (Bekker \& Boselie, 2002).

Work stress experienced by individuals could cause various problems, such as the inability to relax or concentrate, difficulty thinking logically, and making the decisions, feeling depressed and irritable. In addition, a person might also have problems with sleeping, feeling tired, depressed, or anxious, or even serious physical problems such as heart disease, disorders of the digestive system, increased blood pressure, headaches, or muscular-skeletal disorders (Leka et al., 2004). When workers suffered stress and did not get enough support or were not aware of ways to manage the stress, they might also engage in unhealthy activities, such as smoking, consuming alcohol or taking drugs (Leka et al., 2004).

According to the existing literature, there were four things as reactions to job stress namely: going out, voicing, loyalty, and neglect (Farrell, 1983 cited by Hon, Chan, \& Lu, 2013). Workers could choose to leave the organization (leave), they could choose to remain and become actively involved in seeking improvements and reducing sources of stress (voicing), some might decide to remain in the company and accept the situation as it was without any effort to increase it (loyalty), or they could still and passively display withdrawal behavior.

\section{Emotional labor and employee creativity}

Based on the cognitive perspective on emotional work, both surface acting and deep acting could display the desired emotion, they involved different cognitive processes in emotional management and did not have the same efficiency in consuming cognitive resources available in the creation of creative ideas during service delivery (Mikolajczak, Tran, Brotheridge, \& Gross, 2009). Surface acting occurred relatively late in the process of regulation of emotional cognition without reassessment of the situation or environment such as the regulation of emotions that focused on response. Frontline employees would fake their emotional appearance without changing their inner feelings about the work environment. So, during service, they had to monitor their emotional expression cues from time to time to change the emotion shown in accordance with the display rules and repeated the process of regulation over and over again.

Without sufficient cognitive resources to develop skills that were relevant to the creative and relevant to the domain during service discovery, frontline employees in using surface acting could not produce creative ideas. Richards and Gross (2000) suggested that surface acting required employees to invest more cognitive resources, which could damage their cognitive performance abilities even if the customer was not aware that the employee was involved in surface acting.

\section{H1: Emotional labor has a negative effect on employee creativity.}

\section{Emotional labor and turnover intention}

Surface acting as a form of emotional labor was done by faking the desired emotional appearance without changing his/her internal feelings (Hochschild, 1983). Employees involved in surface acting felt tension when they felt they had to display emotions that were different from their authentic emotions. Emotional dissonance would often occur when employees were 
involved in surface acting (Biron \& Van Veldhoven, 2012). Research on emotional dissonance had shown that this experience was very uncomfortable for employees, and employees were ultimately motivated to quit the emotional dissonance that occurs (Abraham, 1999).

Unintentional emotional regulation to conform with organizational service display rules could require service providers to spend extra on psychological resources. This would drain their level of involvement and energy. Chau et al (2009) and Goodwin (2011) found that surface acting was positively related to fatigue and turnover intention.

\section{H2: Emotional labor has a positive effect} on turnover intention.

\section{Emotional labor and work stress}

In applying the emotional labor, employees had to display surface acting to suppress to suppress their negative emotions. Conversely, deep acting showed that workers modified their feelings to match the emotional expressions requested by management. Through deep acting, employees would manage their feelings accordingly within themselves. However, attempted to display positive emotions or suppressed negative emotions often lead to physiological response patterns that indicated somatic disease (Schaubroeck \& Jones, 2000). The general argument was that emotional work involved false facial acting such as expressing emotions while suppressing opposite inner feelings, and that false face could lead to negative physical and psychological outcomes, such as work stress and fatigue (Schaubroeck \& Jones, 2000).

Maslach states that individuals who were emotionally exhausted were those who were involved in emotionally charged situations on a regular basis. He further pointed out that because it was a common belief that service providers themselves were responsible for ensuring the future wellbeing of their customers and clients, this belief is also an amazing but tiring burden for service providers (Maslach, 1982). This view was supported by empirical research that had shown that employees who interacted with customers frequently and continuously (excessive role forms) were found to suffer from higher levels of emotional fatigue (Saxton, Phillips, \& Blakeney, 1991).

H3: Emotional labor has a positive effect on work stress.

\section{Job stress and employee creativity}

When surface acting increased the pressure on the frontline, they had a bad idea of how their tasks were related to customer needs, with the work of other service providers and for the overall purpose of service companies. This made it difficult for employees to decide on the best way to complete their assignments and prevented them from developing skills relevant to the domain and using creative thinking skills in carrying out service work. With stress constraints, frontline employees felt that the problem cannot be solved, and the situation would not change; as such, they would choose a passive response by accepting the status quo without making improvements (loyalty) or showing disregard for behavior. Loyalty and neglect eroded employee creativity, Coelho \& Augusto (2010) found that work stress related to role ambiguity reducing the creativity of frontline in the service context. Therefore, the pressure caused by surface acting reduced the creativity of frontline employees.

The literature shows that work stress was not only a determinant of employee creativity but also an important mediator between the relationship of contextual factors and employee creativity/ performance (Coelho \& Augusto, 2010, Hon, Chan, \& Lu, 2013)

H4: Work stress has a negative effect on employee creativity.

\section{Job stress and turnover intention}

When there were many jobs demands, stress arose and lead to turnover intention. Job resources also stimulated shifting intentions. Substitution depended on many personal and impersonal reasons and a person left a job when he found another job easily or he had other opportunities. The intention to stop always had high costs and negative results. Kumar and Govindarajo (2014) stated that several instruments were available in the literature to measure several concepts such as absenteeism and retention 
If the level of work stress of employees exceeded acceptable limits, this could cause employees to face physical, psychological, and sociological problems and be unhappy. In this case there was a view that the activities of the organization where they work or the work they do was a source of stress, so employees voluntarily moved away from the organization and might want to get rid of problems caused by stress. Choi et al. (2013) and Yenihan et al., (2014) showed that stress increased turnover intentions.

H5: Work stress increases the turnover intention of frontline employees.

\section{METHODS}

\section{Data Collection}

Quantitative data collection is done by the census method using questionnaire distribution techniques to 90 employees of Bank BTN Semarang Branch. Because using the census method, the number of questionnaires distributed was adjusted to the total number of more frontline employees, namely 90 people, using a scale of 5 .

\section{Measurement}

Emotional labor was measured with acting surface dimension used by Diefendorff et al. (2005) and Geng, et al (2014) with 7 items 5-point without using deep acting. The measurement of work stress was carried out by adopting the Cavanaugh (2000) scale (2000) and (Geng et al., 2014) with 11 items with language adjustment. The scale of work stress measurement used 5 items. Creativity was measured with a scale developed by Geng et al., (2014) which consists of 5 items. The turnover intention was measured with scale developed by Sheraz et al. (2014) which consist 3 items..

\section{RESULTS AND DISCUSSION}

\section{Measurement model (outer model)}

The results showed that not all items had a good loading factor. In this case, 5 items namely el1, sk1, sk8, sk10 and sk11 had loading factor below 0.70 . For these five items were excluded from the analysis so that the research model experienced a change in the number of indicators with the results of changes in the loading and crossloading values.

Table 1.

Outer loading

\begin{tabular}{ccccc}
\hline & EMOLABOR & WORK STRESS & CREATIVITY & TURNOVER \\
\hline el2 & 0,798 & & & \\
el3 & 0,719 & & & \\
el4 & 0,768 & & & \\
el5 & 0,923 & & & \\
el6 & 0,845 & & & \\
el7 & 0,756 & & & \\
sk2 & & 0,746 & & \\
sk3 & & 0,806 & & \\
sk4 & & 0,727 & & \\
sk5 & & 0,789 & & \\
sk6 & & 0,789 & & \\
sk7 & & 0,711 & & \\
sk9 & & 0,717 & 0,816 & \\
kk1 & & & 0,916 & \\
kk2 & & & 0,906 & \\
kk3 & & & 0,964 & \\
kk4 & & & 0,836 & 0,920 \\
kk5 & & & & 0,806 \\
ti1 & & & & \\
ti2 & & & & \\
ti3 & & & & \\
\hline
\end{tabular}


Table 2.

Cross loading

\begin{tabular}{rrrrr}
\hline & EMOLABOR & WORK STRESS & \multicolumn{1}{c}{ CREATIVITY } & \multicolumn{1}{c}{ TURNOVER } \\
\hline el2 & 0,798 & 0,103 & $-0,040$ & 0,273 \\
el3 & 0,719 & 0,216 & 0,030 & 0,318 \\
el4 & 0,768 & 0,202 & $-0,076$ & 0,282 \\
el5 & 0,923 & 0,361 & $-0,097$ & 0,432 \\
el6 & 0,845 & 0,164 & $-0,022$ & 0,344 \\
el7 & 0,756 & 0,255 & $-0,107$ & 0,251 \\
sk2 & 0,183 & 0,746 & $-0,191$ & 0,336 \\
sk3 & 0,227 & 0,806 & $-0,161$ & 0,352 \\
sk4 & 0,129 & 0,727 & $-0,273$ & 0,394 \\
sk5 & 0,191 & 0,789 & $-0,192$ & 0,291 \\
sk6 & 0,231 & 0,789 & $-0,164$ & 0,338 \\
sk7 & 0,285 & 0,711 & $-0,295$ & 0,382 \\
sk9 & 0,253 & 0,717 & $-0,288$ & 0,263 \\
kk1 & $-0,045$ & $-0,262$ & 0,816 & $-0,302$ \\
kk2 & 0,006 & $-0,258$ & 0,916 & $-0,288$ \\
kk3 & $-0,080$ & $-0,278$ & 0,906 & $-0,500$ \\
kk4 & $-0,047$ & $-0,312$ & 0,964 & $-0,415$ \\
kk5 & $-0,159$ & $-0,224$ & 0,836 & $-0,473$ \\
ti1 & 0,372 & 0,383 & $-0,397$ & 0,920 \\
ti2 & 0,409 & 0,344 & $-0,353$ & 0,926 \\
ti3 & 0,293 & 0,465 & $-0,421$ & 0,806 \\
\hline
\end{tabular}

By excluding the 5 indicators, the study had a total of 21 indicators. The results of the second stage measurement model of this research model is presented in the following loading factor table (Table 1) for outer loading.

Table 1 showed that after removing the EL1, SK1, SK8, SK10, and SK11 indicator items, all other items had a loading factor that had exceeded the recommended value of 0.70 .

\section{Discriminant validity}

Discriminant validity was assessed using cross-loading values, compared the correlation between construct and square root of the extracted mean variant (AVE) for the construct. Cross loading indicates that all measurement items loads clearly on the specified latent variable intended to measure the variable. The values of crossloading on indicators to measure variables corresponding to latent variables were the biggest value compared to the indicator value for variables that did not coincide. The correlation of latent variables and AVE square root values were obtained as follows in Table 2.

Table 2 displayed the correlation matrix for the construct. The results showed adequate discriminant validity for all constructs in the proposed conceptual model. Based on the analysis conducted, the measurement model in this thesis showed adequate discriminant validity which meant that all latent variables proposed in the hypothesis model differed from one another. In sum, the measurement model in this thesis showed adequate convergent validity and discriminant validity.

\section{Reliability and variance extracted}

Reliability is presented in several sizes, namely composite reliability, Cronbach Alpha, and AVE. Composite reliability of the construct obtained ranged from 0.903 to 0.950 which exceeds the recommended value of 0.70 (Hair, et. al, 2011). Cronbach's alpha is used to assess item consistency between measurement items. Cronbach's alpha of all latent variables ranged from 0.860 to 0.933 so it exceeds the recommended value of 0.60 (Nunnaly, 1994). The AVE results also provide additional support for convergent validity. The extracted average variant (AVE) which measures the variance captured by the

Table 3.

Reliability and AVE

\begin{tabular}{lccc}
\hline & $\begin{array}{c}\text { Composite } \\
\text { Reliability }\end{array}$ & $\begin{array}{c}\text { Cronbach } \\
\text { Alpha }\end{array}$ & AVE \\
\hline Emolabor & 0.916 & 0.890 & 0.647 \\
Workstress & 0.903 & 0.875 & 0.571 \\
Creativity & 0.950 & 0.933 & 0.791 \\
Turnover & 0.916 & 0.860 & 0.785 \\
\hline
\end{tabular}




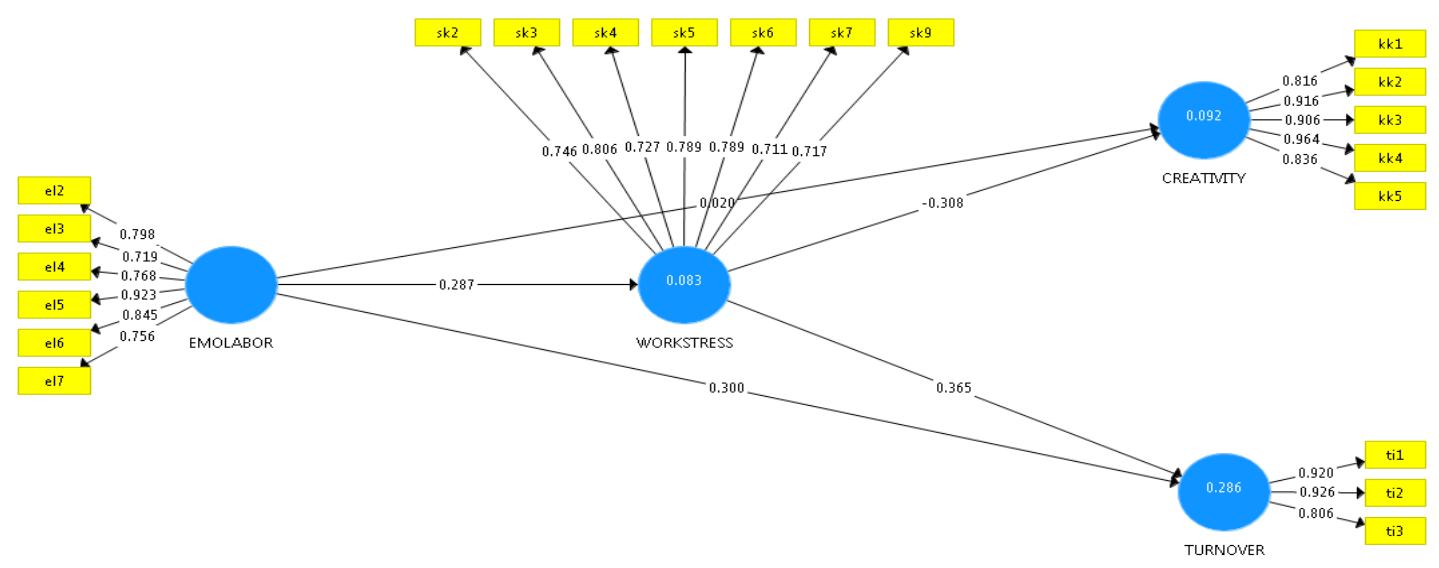

Figure 2.

Result of PLS processing

indicator relative to the measurement error, is obtained in the range of 0.571 and 0.791 . Overall, the results show that all constructs are valid measures based on their estimated parameters, which show reasonable convergent validity.

\section{Structural model (inner model)}

The measurement model has been shown to have good individual item reliability, convergent validity, and discriminant validity. With all values within the acceptable standard limits, the measurement model in this study shows that sufficient resistance is needed to test the relationship between exogenous and endogenous variables.

\section{Coefficient of determination of $\mathbf{R}^{\mathbf{2}}$}

The value of $R^{2}$ determined the predictive power of the model. Adjusted $\mathrm{R}^{2}$ on the Job Stress variables showed a value of 0.083 . This means that $8.3 \%$ of work stress could be influenced by emotional labor variables.

Adjusted $\mathrm{R}^{2}$ at the employee creativity variable indicated a value of 0.092 . This means that $9.2 \%$ of employee creativity could be influenced by emotional labor and work stress variables. Adjusted $\mathrm{R}^{2}$ in the variable turnover intention showed a value of 0.286 . This means that $28.6 \%$ turnover intention could be influenced by emotional labor and work stress variables (see Table 4).

\section{Hypothesis testing}

The hypothesis testing was achieved by looking at the sign, size and statistical significance of the path coefficient (b) between the latent independent variable and the dependent variable. The higher the path coefficient, the stronger the LV effect on the dependent variable. The results of the path coefficient testing of the tested model are based on the results of the PLS analysis of the SmartPLS software. Presented in Figure 2 and Table 5 below. The results of testing the effects, not from the applied model were obtained as displayed in Table 6.

The influence of emotional labor on creativity mediated by work stress showed a significance value of $0.106>0.05$ which meant that work stress did not mediate the effect of emotional labor on employee creativity. On the other hand, work stress could be obtained to mediate emotional labor on turnover intention in a positive direction. This meant that turnover intention could be formed from work stress which could also be caused by emotional labor.

\section{Discussion}

Hypotheses about the effects of surface acting that decreased the frontline employee creativity were not found in this study. This means that although employees did the surface acting, it seemed that the thing directly did not make employees experienced a decrease in their creativity. One explanation of this might occur was because the characteristics of

Table 4.

$\mathbf{R}^{2}$ and adjusted $\mathbf{R}^{2}$

\begin{tabular}{lcc}
\hline \multicolumn{1}{c}{ Variable } & $\mathbf{R}^{2}$ & ${\text { Adj } \mathbf{R}^{2}}^{2}$ \\
\hline Workstress & 0.083 & 0.072 \\
Creativity & 0.092 & 0.071 \\
Turnover & 0.286 & 0.269 \\
\hline
\end{tabular}


Table 5.

Hypothesis testing

\begin{tabular}{lccc}
\hline \multicolumn{1}{c}{ Hypothesis } & beta & P-value & Information \\
\hline H1: Emotional labor for creativity & 0.020 & 0.886 & Rejected \\
H2: Emotional labor towards tunover intention & 0.300 & 0,000 & Received \\
H3: Emotional labor to work stress & 0.287 & 0.017 & Received \\
H4: Job stress on Creativity & -0.308 & 0.006 & Received \\
H5: Job stress on turnover intention & 0.365 & 0,000 & Received \\
\hline
\end{tabular}

frontline service employee assignments in Indonesia banking might not require much employee creativity. Frontline employee time seemed to be more widely used to follow company instructions to standardize the service delivery process, making service tasks routine and less complex.

Besides not having a significant effect, the direction of the coefficient was positive which showed that even though the frontliner dod emotional labor, it actually slightly increased the creativity. This might be due to the age difference owned by the frontliners.

In this study, older frontliner employees including frontliners over the age of 25 had an equal number of younger frontliner under the age of 25. According to Binneweis et.al (2008), conditions of work that have high control will have a relationship between age and creativity of positive ideas, while the relationship will be negative in conditions of low job control. In this case the creativity of older employees did not appear to be different at high or low levels of job control. A high level of work control did not foster the creativity of older employees and it seemed that a low level of work control would reduce the creativity of older employees. Older employees might have learned to be creative at work on certain workplace characteristics, such as the level of unfavorable job control. Creative ideas, in this situation, can include changing the situation at work when needed. Older employees might have the experience and

Table 6.

Indirect effects

\begin{tabular}{lcc}
\hline \multicolumn{1}{c}{ Hypothesis } & beta & P-value \\
\hline $\begin{array}{l}\text { Emolabor->Workstress- } \\
\text { >Creativity }\end{array}$ & $-0,089$ & 0,106 \\
$\begin{array}{l}\text { Emolabor->Workstress-> } \\
\text { Turnover }\end{array}$ & 0,105 & 0,029 \\
\hline
\end{tabular}

confidence to develop creative ideas independent of the level of job control.

Conversely, the creativity of younger employees was largely different in conditions of high and low work control. Younger employees seemed to be most creative when experiencing low job control, whereas they appear to be less creative in situations with high job control. According to De Jonge and Schaufeli, 1998, younger employees might lack the skills to successfully handle this demand and take advantage of high levels of job control. In jobs with low job control, clear guidance on how to carry out work assignments were given, and this guide could be a useful and important starting point for younger employees to foster creativity. At work with high control, this useful guide might be lost and could generate ideas that are less creative among younger employees.

Emotional labor is one of the job controls because the organization pays frontliners with the task of displaying the emotions the organization wants to frontliners so that there is a possibility that frontliner variations with relatively young age with little experience will enable them to have the ability to do different surface acting compared with frontliners who are quite old so that the level of creativity varies greatly, and in an almost balanced composition between frontliners under the age of 25 years and those above the age of 25 , it made the level of creativity insignificant.

Results of testing hypothesis 2 showed that emotional labor surface acting had a positive influence on turnover intention. As such, it was consistent with previous theories (Brotheridge \& Grandey, 2002). The results of this study also supported previous theoretical models that showed that emotional labor strategies could have differential

$$
\text { effects }
$$


on turnover intention behavior (Grandey, 2000).

As previous theoretical studies, surface acting was generally associated with more damaging results for individuals and organizations. Theoretical support for the influence of surface acting on turnover intentions could be found in theory and research on emotional dissonance (Grandey, 2000). Research on emotional dissonance showed that experiences of surface acting made themselves uncomfortable, and consequently employees were motivated to avoid themselves from situations where emotional dissonance occurred, so emotional dissonance could result in increased intention to move because emotional dissonance and surface acting were constructive constructs. conceptually similar (Grandey, 2003)

This study showed that bank workers who provided interpersonal services for customers or clients, apart from jobs that involved greater emotional specifically in the form of surface acting showed a greater level of work stress than employees who did not interact directly with clients. This group of frontline employees shows that surface acting was directly related to increased work stress. In this study, the research score of job stress could be a good indicator of the status of associated mood representatives among frontline employees. Previous research also reported that surface acting played a role in increasing work stress.

As revealed in this analysis, a positive relationship was found between emotional labor and work stress, which meant that hiding emotions as a sub-dimension of emotional labor had a positive and significant relationship with personal fatigue, work-related fatigue, and client-related fatigue as well as false emotions also had a positive and significant relationship with work stress. In previous studies, the same results were obtained that surface acting could increase work stress (Geng. et al, 2014). Thus the increase in surface acting i,e hiding, and faking emotions would increase work stress. Likewise, previous studies noted a positive and significant effect of hiding emotions in explaining emotional exhaustion.

Significant results from this study were found to validate the emotional labor theory (Grandey, 2000; Hochschild, 1983) where surface acting had shown an association with emotional exhaustion. Generally, the results showed that surface acting has a negative effect on employees. During doing surface acting, service workers wore emotional masks, which involved the expression of feelings that were actually felt and instead of expressing emotions they did not actually feel. This further implied that the service workers who engaged regularly in surface acting felt a loss of personal authenticity (Brotheridge and Lee, 2003). On an ongoing basis, this caused the feelings of alienation and the alienation from one's feelings (Hochschild, 1983) which then caused feelings of emotional exhaustion.

Bank frontline staff often complained about high enough stress because they are faced with a growing number of older consumers. This is because young people might refer online activities or transactions. The elderly is respected in Indonesian culture and so the frontliner required more patience, which increases the pressure on the frontline staff.

Someone desired to maintain the resources they value for their own individual development, and one of these resources was energy, including emotions, interests, passions, and so on (Chapman, 2009). When a person's psychological resources were consumed without timely replenishment, emotional disturbances and low performance could occur (Lopes, et.al, 2005). Specifically, this study demonstraed the intrinsic mechanism in which emotional disturbances played a mediating role between emotional labor and turnover intention at least among the bank frontline staff in BTN. Research findings also showed that employees and organizations had to pay more attention to the psychological resources of employees because it could reduce emotional disturbances. In this case, future studies could find ways to increase and replenish psychological resources of employees so as to improve their wellbeing. Researchers could consider and incorporate variables, such as individual nature, organizational support, and explore the mechanism of influence, to design and provide more accurate employee assistance programs.

This study also clarified the underlying mechanism regarding the type of surface acting and its effect on work stress. While previous research on emotional work shows that deep acting is far 
more valuable than surface acting, this research explores the mechanisms underlying this relationship. The emotional labor of employees could cause psychological fatigue, which consumed psychological resources (Brotheridge and Lee, 2003). If employees' emotional experienced conflict with what is demanded of them, they will experience cognitive imbalances. They would try to compensate for this inappropriate emotional expression, making them more vulnerable to emotional imbalances (Grandey, 2003). Without timely replenishment, employees experienced high work pressure, low self-efficacy, and emotional exhaustion, which causes work fatigue and low job satisfaction.

The results of this study settled that job stress had a negative influence on creativity. This meant that great work stress experienced by employees would reduce creativity. The findings from this study showed the negative effects of stress on creativity. Several other researchers had also found evidence of negative effects of stress on creativity (Geng, et a; 2014 and Hon et al., 2013)

Creativity was important for an organization's competitive advantage because all innovations began with creative ideas (Amabile, et.al, 1996). When employees thought creatively, they often came up with new suggestions and ideas that provided the organization with important raw materials for further development. Creativity was a necessary condition for innovation but not alone enough for it. In the area of organizational behavior, creativity referred to the creation of useful new products, practices, services and procedures. Creativity was needed for organizational survival, espsecially in a rapidly changing environment (Baer, Oldham and Cumings, 2003).

Stress produced behavior that could interfere with creative responses. In other words, when employees were affected by stress, they tended to take habitual actions and left creative actions. This finding was consistent with the disorder theory which states that people have limited mental resources, and when under stress, they would devote some resources to dealing with stressors. This created a situation where stressed people are left with less cognitive resources for other tasks such as creative thinking (Byron et al., 2010). Therefore, when people experienced stress, creative thoughts would tend to decrease.

However, Anderson, De Dreu, and Nijstad (2004), reviewing the literature on creativity and innovation, argued that stress could increase creativity. Based on their findings, stress increased arousal which encourages the use of creative thinking. Anderson et al. (2004) asserted that when people were exposed to stress, they were involved in focused problemsolving strategies that lead to increased creativity. As a result, stress could increase creativity by creating demand for creative solutions and by providing cognitive stimulation. Thus, stress could increase right or decreases creativity.

However, it made sense in this study to find that individuals who experienced stress could show lower creativity. People under stress tended to show focus and stereotypes narrow that inhibit creativity.

The findings of this study indicated that stress had a significant influence on creativity in a negative direction. As far as cognitive tasks we concerned, it was said that creativity and performance, in general, might be at a high level in employees who were not stressed. This implies that in the workplace, if individuals were under pressure, then their level of creativity and performance would be negatively affected.

A number of studies had concluded that stress could have several negative consequences including job dissatisfaction, reduced organizational commitment, absenteeism, and turnover intention. This study empirically found that there was a positive significant relationship between work stress and turnover intention. These results supported the findings of several previous studies, (Choi et al. (2013), Yenihan et al., (2014) and Zahra et.al (2018). These results observed that when work stress increases, turnover intention also increased, and management had the ability to understand that the majority of frontline employees were under work pressure. Therefore, it was necessary to manage the level of work stress among the workers.

Turnover intention referred to a kind of behavior that explains the procedure of leaving or replacing employees in an organization. In management, change was not new but an important issue in human resource management that attracted public interest in practitioners of administration and 
industrial relations management throughout the world. Because there was increased competition, organizations had to develop strategies to retain employees who had a good performance.

The results show that work stress could mediate the effect of emotional labor on employee creativity and turnover intuition. This meant that a decrease in employee creativity and an increase in turnover intention could be proven by first obtaining work stress by frontline employees. This could clearly be shown in the effect of emotional labor on employee creativity where emotional labor dud does not have a direct influence on employee creativity, but emotional labor would decrease employee creativity when emotional labor first created work stress.

Slighly different emotional labor also had a direct or indirect effect on turnover intention through work stress. This meant that emotional labor would create work stress on frontline employees. Job stress experienced by employees could result in the desire of employees to quit their jobs.

\section{CONCLUSION}

\section{Implications}

In accordance with the explanation of the emotional labor, that frontline employees are asked by the company to follow the service provisions in accordance with company rules, making them do the maximum effort, such as changing emotions that are felt in accordance with emotions required by the company. In addition, because of the company's demands related to employee emotions, it causes work stress and the desire to leave the company because these demands provide inconvenience at work.

The findings of this study have important implications for frontline employee emotional labor management, work stress management, creativity, and turnover intention. To increase frontline employee creativity and customer service performance, especially the role of performance, acting in addition to surface acting must be encouraged. Service companies must designate frontline service work for employees who are willing and inclined to adjust their inner feelings to match the emotions requested by the display rules. What's more, because in-depth acting can be learned (Morris, \& Feldman, 1996), corporate services can invite some psychological experts or professional trainers to help frontline service employees master their skills and approach to acting.

The mediating effect of frontline employee work stress between emotional labor with employee creativity and turnover intention increases trust in deep acting impulses. Managers can identify whether adjustments to emotional labor strategies have an effect on employee creativity and decrease employee turnover intention by monitoring changes in work stress obtained by frontline employees, to determine whether in-depth actions by frontline service employee neet to be further stimulated.

In addition, the implications that can be obtained about inspiring employee creativity by reduing work stress frontline service employees. Previous studies found that job characteristics such as work autonomy, variety, feedback, and identity as well as compensation and reward systems are variables that can reduce job stress, thus, service managers can manage work stress for frontline service employees by increasing frontline service employee autonomy, enlarging a series of activities carried out by employees to include variations to front-line services, providing more task feedback and increasing compensation and rewards. By taking these steps, frontline service employees will be motivated to develop more creative solutions to customer problems and do better customer service.

\section{Limitations and further research}

There are several limitations that must be overcome and recommended for further research. First, this research was only conducted on frontline service employees at Bank BTN Semarang, so it cannot be ascertained that the results of the study will be the same if applied to other service organizations with different organizational and occupational characteristics. Wider testing of this model will be an important step for future research. Second, the study is limited to the dimensions of the surface acting in assessing emotional labor. Future studies can use deep acting and surface acting in explaining emotional labor strategies. Third, by seeing that creativity can also be influenced by age aspects of frontliners and other individual aspects, further research can be developed by adding 
age factors in moderating the influence of emotional labor on creativity. Fourth, in this study, there is a relationship between employee creativity with turnover intention, but research is not done so that to further this variable can be tested research.

\section{REFERENCES}

Abraham, R. (1999). The impact of emotional dissonance on organizational commitment and intention to turnover. Journal of Psychology: Interdisciplinary and Applied, 133 (4), 441-455.

Adrian, T., \& Ashcraft, AB (2012). Shadow Banking: A Review of the Literature. SSRN Electronic Journal.

Ali, WU, Raheem, AR, Nawaz, A., \& Imamuddin, K. (2014). Impact of Stress on Job Performance: An Empirical Study of the Employees of Private Sector Universities of Karachi, Pakistan. Research Journal of Management Sciences, 3 (7), 14-17.

Amabile, TM (1985). Motivation and Creativity. Effects of Motivational Orientation on Creative Writers. Journal of Personality and Social Psychology, 48 (2), 393-399.

Amabile, TM, Schatzel, EA, Moneta, GB, \& Kramer, SJ (2004). Leader behavior and the work environment for creativity: Perceived leader support. Leadership Quarterly, 15 (1), 5-32.

Anbazhagan, A., Rajan, LJS, \& Ravichandran, A. (2013). Work stress of hotel industry employees in Puducherry. Asia Pacific Journal of Marketing \& Management Review, 2 (5), 85-101.

Anderson, N., De Dreu, CKW, \& Nijstad, BA (2004). The routinization of innovation research: A constructively critical review of the state-of-the-science. Journal of Organizational Behavior, 25 (2), 147173.

Andrew Morris, J., \& Feldman, DC (1996). The dimensions, antecedents, and consequences of emotional labor. Academy of Management Review, 21 (4), 986-1010.

Ashforth, BE, \& Humphrey, RH (1993). Emotional Labor in Service Roles: The Influence of Identity. Academy of Management Review, 18 (1), 88-115.

Baer, M, Oldham, GR and Cummings, A, 2003, Rewarding creativity: When does it really matter? , The Leadership Quarterly 14 (4): 569-586,

Bekker, MHJ, \& Boselie, KAHM (2002). Gender and stress: Is gender a role stress? A reexamination of the relationship between feminine gender role stress and eating disorders. Stress and Health, 18 (3), 141-149.

Bhatti, N., Shar, AH, Shaikh, FM, \& Suhail Nazar, M. (2010). Causes of Stress in Organization, a Case Study of Sukkur. International Journal of Business and Management, 5 (11), 314.

Binnewies, C., Sonnentag, S., \& Mojza, EJ (2009). Feeling Recovered and Thinking About the Good Sides of One's Work. Journal of Occupational Health Psychology, 14 (3), 243-256.

Biron, M., \& van Veldhoven, M. (2012). Emotional labor in service work: Psychological flexibility and emotion regulation. Human Relations, 65 (10), 1259-1282.

Blau, FD, \& Kahn, LM (2007). The gender pay gap. Economists' Voice, 4 (4).

Boshoff, C., \& Mels, G. (2000). The Impact of Multiple Commitments on Intentions to Resign: An Empirical Assessment. British Journal of Management, 11 (3), 255-272.

Brennan, EM, \& Brannan, AM (2005). Participation in the paid labor force by caregivers of children with emotional and behavioral disorders. Journal of Emotional and Behavioral Disorders, 13 (4), 237-246.

Brotheridge, $\mathrm{CM}$ and Lee, R, T, (2003), Development and validation of the Emotional Labor Scale, Journal of Accupational and Organizational Psychology, Volume76, Issue3, Pages 365-379

Brotheridge, $\mathrm{CM}, \quad \& \quad$ Grandey, $\mathrm{AA}$ (2002). Emotional labor and burnout: Comparing two perspectives of "people work." Journal of Vocational Behavior, 60 (1), 17-39.

Cavanaugh MA1, Boswell WR, Roehling MV, Boudreau JW. (2000), An empirical examination of self-reported work stress among US managers. J Appl Psychol. Feb; 85 (1): 65-74.

Celikyay , M and Akgün, AK, (2019), The Influences Of Emotional Labor Mechanisms On The Project Team's Creativity and Performance, Kafkas Üniversity Economics and 
Administrative Sciences Faculty of KAUJEASF , Vol. 10, Issue 19, 2019 ISSN: 1309 - 4289

Chapman, H, Kim , DA, Susskind, JM, Anderson A, (2009), In Bad Taste: Evidence for the Oral Origins of Moral Disgust . Science, 323 (5918): 1222-6,

Chau, SL, Dahling, JJ, Levy, PE, \& Diefendorff, JM (2009). A predictive study of emotional labor and turnover. Journal of Organizational Behavior, 30 (8), 11511163.

Choi, SPP, Cheung, KIN, Pang, SMC (2013), Attributes of nursing work environments as predictors of registered nurses job satisfaction and intention to leave. Journal of Nursing Management, 21 (3), 429-439.

Coelho, F., \& Augusto, M. (2010). Job characteristics and the creativity of frontline service employees. Journal of Service Research, 13 (4), 426-438.

Conrad, C., \& Witte, K. (1994). Is Emotional Expression

Repression Oppression? Myths of Organizational Affective Regulation. Annals of the International Communication Association, 17 (1), 417-428.

Cooper, CL, Dewe, PJ, \& O'Driscoll, MP (2001). Foundations for organizational science. Organizational stress: A review and critique of theory, research, and applications. Sage Publications, Inc.

Cox, T. (1993). Stress Research and Stress Management: Putting theory to work (pp. 1-20). pp. 1-20.

De Cuyper, N., Mauno, S., Kinnunen, U., \& Mäkikangas, A. (2011). The role of job resources in the relationship between perceived employability and turnover intention: A prospective two-sample study. Journal of Vocational Behavior, 78 (2), 253-263.

De Jonge, J., \& Schaufeli, WB (1998). Job characteristics and employee wellbeing: A test of Warr's Vitamin Model in health care workers using structural equation modeling. Journal of Organizational Behavior, 19 (4), 387407.

Diefendorff, JM, Croyle, MH, \& Gosserand, RH (2005). The dimensionality and antecedents of emotional labor strategies. Journal of Vocational Behavior, 66 (2), 339-357.

Eisenhardt, KM, \& Tabrizi, BN (1995). Accelerating Adaptive Processes: Product Innovation in the
Global

Industry. Quarterly, 40 (1), 84.

Elangovan, AR (2001). Causal ordering of stress, satisfaction and commitment, and intention to quit: A structural equations analysis. Leadership \& Organization Development Journal, 22 (4), 159-165.

Erickson, RJ, \& Wharton, AS (1997). Inauthenticity and depression: Assessing the Consequences of interactive service work. Work and Occupations, 24 (2), 188-213.

Feist, GJ (1998). A meta-analysis of personality in scientific and artistic creativity. Personality and Social Psychology Review, 2 (4), 290-309.

Fink, G. (2009). Stress: definition and history. In: Squire L, ed-in-chief. Encyclopedia of Neuroscience. Oxford: Elsevier Ltd;

Geng, Z., Liu, C., Liu, X., \& Feng, J. (2014). The effects of emotional labor on frontline employee creativity. International Journal of Contemporary Hospitality Management, 26 (7), 1046-1064.

Geroski, P, Machin, S and Van Reenen, John (1993) The profitability of innovating firms. RAND Journal of Economics, 24 (2). pp. 198-211

Gong, Y, Huangm Jia-Chi and Farhm Jiing-Lih, (2009), Employee Learning Orientation, Transformational Leadership, and Employee Creativity: The Mediating Role of Employee Creative SelfEfficacy , Academy of Management Journal Vol. 52, No. 4Articles

Goodwin, C., Radford, R., (1993) 'Models of service delivery: an integrative perspective' Advances in Services Marketing and Management, Vol. 2, pp. 231-252.

Goodwin, RE (2011). The Impact of Emotional Labor Strategies on Organizational Outcomes.

Grandey, AA (2000). Emotion regulation in the workplace: a new way to conceptualize emotional labor. Journal of Occupational Health Psychology, 5 (1), 95-110.

Grandey, Alicia A, Diefendorff, JM, \& Rupp, DE (2013). Emotional Labor in the 21st Century Diverse Perspectives.

Hochschild, A., Irwin, N., \& Ptashne, M. (1983). Repressor structure and the mechanism of positive control. Cell, 32 (2), 319-325.

Hon, AHY, Chan, WWH, \& Lu, L. (2013). Overcoming work-related stress 
and promoting employee creativity in the hotel industry: The role of task feedback from supervisors. International Journal of Hospitality Management, 33 (1), 41624.

Isik, M and Hamurcu , A (2017). The role of job stress at emotional labor's effect on intention to leave: Evidence from call center employees, Business and Economic Horizons (BEH), Prague Development Center, vol. 13 (5), pages 630-651,

Jourdain, G., \& Chenevert, D. (2010). Job demands-resources, burnout and intention to leave the nursing profession: A questionnaire survey. International Journal of Nursing Studies, 47 (6), 709722.

Karabanow, J. (1999). When caring is not enough: Emotional labor and youth shelter workers. Social Service Review, 73 (3), 340-357.

Kumar, MD, \& Govindarajo, NS (2014). Instrument Development: "Intention to Leave Instrument" (ILI). Middle-East Journal of Scientific Research, 21 (3), 509-517.

Leka, S., Griffiths, A. \& Cox, T (2004), Work Organizations \& Stress, Systematic Problem Approaches for Employers, Managers and Trade Union Representatives $s$ retrieved on 5 June 2009

Liu, C., Liu, X., \& Geng, Z. (2013). Emotional labor strategies and service performance: The mediating role of employee creativity. Journal of Applied Business Research, 29 (5), 1583-1596.

Lopes PN, Salovey P, Cote S, Beers M. Emotion regulation abilities and the quality of social interaction. Emotion. 2005; 5 (1): 113-118

Maslach, C. (1982). Understanding burnout: Definitional issues in analyzing a complex phenomenon. Job stress and burnout. a Complex Phenomenon: Job Stress and Burnout, (January 1982). Retrieved from http s: //scholar.google.com/scholar?

Mikolajczak, M., Tran, V., Brotheridge, CM, \& Gross, JJ (2009). Chapter 11: Using an emotion regulation framework to predict the outcomes of emotional labor. In Research on Emotion in Organizations (Vol. 5).

Nath, V. (2011). Aesthetic and emotional labor through stigma: National identity management and racial abuse in offshored Indian call centers. Work,
Employment and Society, 25 (4), 709725.

Olsen, KM, Sverdrup, T., Nesheim, T., \& Kalleberg, AL (2016). Multiple functions of commitment in a professional service firm: balancing complex employment relations. Human Resource Management Journal, 26 (4), 390-407.

Ram, N., Khoso Dr., I., Shah, AA, Chandio, FR, \& Shaikih, FM (2011). Role conflict and role ambiguity as factors in work stress among managers: A case study of manufacturing sector in Pakistan. Asian Social Science, 7 (2), 113-117.

Richards, JM, \& Gross, JJ (2000). Emotion regulation and memory: The cognitive costs of keeping one's cool. Journal of Personality and Social Psychology, 79 (3), 410-424.

Ross, G. (1997), "Career stress responses among hospitality employees", Annals of Tourism Research, Vol. 24 No. 1, pp. 4551.

Runco, MA (2007). Creativity: Theories and themes: Research, development, and practice. Elsevier Academic Press

Saxton, MJ, Phillips, JS, \& Blakeney, RN (1991). Antecedents and Consequences of Emotional Exhaustion in the Airline Reservations Service Sector. Human Relations, 44 (6), 583-595.

Schaubroeck, J., \& Jones, JR (2000). Antecedents of workplace emotional labor dimensions and moderators of their effects on physical symptoms. Journal of Organizational Behavior, 21 (2), 163-183.

Schaufeli, W., Tolich, MB, Lo, K., Lamm, F., Conrad, C., Witte, K., ... Ptashne, M. (2012). Shadow Banking: A Review of the Literature. Academy of Management Journal, 2 (1), 376-407.

Sheraz, A., Wajid, M., Sajid, M., Qureshi, WH, \& Rizwan, M. (2014). Antecedents of Job Stress and its impact on employee's Job Satisfaction and Turnover Intentions. International Journal of Learning and Development, 4 (2), 204226.

Shi, Yun-Xia, and Su, Li-Hong (2016). Hotel Frontline Employee's Affective Commitment and Service Creativity: the Mediating Effect of Emotional Labor, Engineering and Technology Research,

Shuler, S., \& Sypher, BD (2000). Eeking motional abor. 14 (1), 50-89. 
Silva, JL, \& Navarro, VL (2012). Work organization and the health of bank employees. Revista Latino-Americana de Enfermagem, 20 (2), 226-234.

Von Nordenflycht, A. (2010). What is a Professional Service Firm? Toward a Theory and Taxonomy of KnowledgeIntensive Firms. Academy of Management Review, 35 (1), 155-174.

Wharton, AS (1999). The Psychosocial Consequences of Emotional Labor. The Annals of the American Academy of Political and Social Science, 561 (1), 158-176.

Yalabik, ZY, Swart, J., Kinnie, N., \& van Rossenberg, Y. (2017). Multiple foci of commitment and intention to quit in knowledge-intensive organizations (KIOs): what makes professionals leave? International Journal of Human Resource Management, 28 (2), 417447.

Yenihan, B., Öner, M., \& Çiftyıldız, K. (2014). İş stresi ve işten ayrılma niyeti arasındaki ilişki: otomotiv işletmesinde beer araştırma [The relationship between job stress and job intention to leave: a research in automotive business]. Çalışma İlişkileri Dergisi, 5 (1), 38-49

Zahra, SS, Khan, MI, Imran, M, Aman, Q and Ali $m$ R, 2018, The relationship between job stress and turnover intentions in the pesticide sector of Pakistan: An employee behavior perspective, Management Issues in Healthcare System, 4 ( 2018) 1-12

Zapf, D. (2002). Emotion of work and psychological well-being. A review of the literature and some conceptual considerations. Human Resource Management Review, 12 (2), 237-268. 